\title{
INFLUENCE OF SELENIUM, COPPER AND ZINC ON PHENOLIC COMPOUNDS IN RYE MALT
}

\author{
Kristina Antonenko*, Viesturs Kreicbergs, Ingmars Cinkmanis \\ ${ }^{1}$ Department of Chemistry, Faculty of Food Technology, Latvia University of Agriculture, Jelgava, LV-3001, Latvia, \\ e-mail: antokrist@inbox.lv
}

\begin{abstract}
The natural phenolic compounds have received increasing interest in the last years due to their role in plants. The aim of this study was to determine the influence of microelements (selenium, copper and zinc) on content of phenolic compounds in rye malt. To obtain rye malt, grains were soaked in water with addition of three mineral salts - sodium selenate $\left(\mathrm{Na}_{2} \mathrm{SeO}_{4}\right)$, copper sulphate $\left(\mathrm{CuSO} 45 \mathrm{H}_{2} \mathrm{O}\right)$ and zinc sulphate $\left(\mathrm{ZnSO}_{4} 7 \mathrm{H}_{2} \mathrm{O}\right)$ at different concentrations of salts. Total and individual phenolic compounds in rye malt were determined by spectrophotometric and HPLC methods. It was identified 19 phenol-type compounds, of which 14 were phenolic acids ( 7 benzoic acid, 6 cinnamic acid and 1 phenylacetic acid derivatives), four flavonoids, and one catechin. Results showed that the majority of determined phenolic compounds were in amount less than $0.1 \mathrm{mg} 100 \mathrm{~g} \mathrm{~g}^{-1} \mathrm{DM}$ and only four of them $(\alpha$-resorcylic acid, protocatechuic acid, catechin and kaempferol) were higher content than $1 \mathrm{mg} 100 \mathrm{~g}^{-1} \mathrm{DM}$. Individual and total phenolic content in rye malt was higher than in non-germinated rye grain. Protocatechuic acid and catechin were not observed in rye samples, but they were present in all malt samples, indicating formation of mentioned substances in germination process.
\end{abstract}

Keywords: microelements, HPLC, spectrophotometric.

\section{Introduction}

Rye (Secale cereale) is a cereal commonly grown in Central and Eastern Europe, especially Poland and Germany (Edney, Izydorczyk 2003). Rye malt is the dried product of rye germinated under controlled conditions and is widely used in the production of bread, food flavouring, as ingredient for bakery products and as colour additive in the preparation of caramel (Antonenko et al., 2013).

Phenolics are the products of secondary metabolism in plants, providing essential function in the reproduction and growth of the plant, acting as defense mechanisms against pathogens and parasites (Gani et al., 2012; Reis Giada, 2013). In food, phenolics may contribute to the bitterness, astringency, colour, flavour, odour, and oxidative stability of products (Naczk, Shahidi 2014). Phenolics are compounds possessing one or more aromatic rings with one or more hydroxyl groups and generally are categorized as phenolic acids, flavonoids, stilbenes, coumarins and tannins (Gani et al., 2012). The most common phenolic compounds found in wholegrain cereals are phenolic acids and flavonoids (Gani et al., 2012; Amarowicz, Weidner 2012). The majority of phenolic compounds are located in the bran (Ondrejovič et al., 2014). Phenolic acids are derivatives of benzoic and cinnamic acids (Gani et al., 2012). Phenolic acids consist of two subgroups: the hydroxybenzoic and hydroxycinnamic acids. Hydroxybenzoic acids include gallic, $p$-hydroxybenzoic, protocatechuic, vanillic and syringic acids. Hydroxycinnamic acids include caffeic, ferulic, $p$ coumaric and sinapic acids (Ozcan et al., 2014). Plant genetics and cultivar, soil composition and growing conditions, maturity state and post-harvest conditions are effective on the quantity and quality of the polyphenols present in plant foods (Ozcan et al., 2014; Gani et al., 2012; Ondrejovič et al., 2014),

Messias (2012), reported that mineral fertilization during the growing season increase the contents of some phenolic compounds, as maintenance of mineral levels is a prerequisite to provide co-factors for many enzymes in the phenylpropanoid pathway. Mineral micronutrients, such as zinc $(\mathrm{Zn})$, and copper $(\mathrm{Cu})$, as well as trace elements, including selenium (Se), have important metabolic functions, acting as cofactors for a number of antioxidant enzymes (Messias et al., 2013). $\mathrm{Cu}$ is known as an essential micronutrient for the function of copper-zinc superoxide dismutases (SOD) and catalase (CAT) which are the most important reactive oxygen species scavenger enzymes. Copper plays an important role in the synthesis of phenolic compounds and its deficiency can decrease phenolics in the plants (Mehrizi et al., 2012). Similarly, Se, for which cereals are an excellent source, is an essential trace element for the regulation of antioxidant metabolism in plants and animals. It functions as a cofactor for glutathione peroxidase, an enzyme that protects tissues against oxidative damage and has a suppressive action on cell proliferation (Messias et al., 2012).

The aim of this study was to determine the influence of microelements: selenium, copper and zinc on phenol content in rye malt.

\section{Materials and Methods \\ Plant material}

Experiments were carried out in Department of Food Technology at the Latvia University of Agriculture. The research object was rye grain (variety 'Kaupo') from Ltd. Naukseni (Latvia). Rye grains of $96 \%$ viability were soaked for $48 \mathrm{~h}$ at $8.5^{\circ} \mathrm{C}$ and there after germinated for $72 \mathrm{~h}$ at $12{ }^{\circ} \mathrm{C}$. Twelve samples of rye malt were prepared. To obtain rye malt, $3 \mathrm{~kg}$ of grains were soaked in $10 \mathrm{~L}$ of water with addition of three mineral salts sodium selenate $\left(\mathrm{Na}_{2} \mathrm{SeO}_{4}\right)$, copper sulphate $\left(\mathrm{CuSO}_{4}\right.$ $\left.5 \mathrm{H}_{2} \mathrm{O}\right)$ and zinc sulphate $\left(\mathrm{ZnSO}_{4} 7 \mathrm{H}_{2} \mathrm{O}\right)$ at different concentrations of salts (Table 1). As a control the samples without microelement additives were used in all experimental series. After germination grains were dried in the oven for 12 hours at temperature of $60{ }^{\circ} \mathrm{C}$ and 12 hours at temperature of $112^{\circ} \mathrm{C}$. Ground in a 
laboratory mill fitted with a $0.4 \mathrm{~mm}$ sieve. Moisture of malt samples ranged from $7.2 \%$ till $8.9 \%$.

Table 1

The content of microelements in water

\begin{tabular}{lcccc}
\hline $\begin{array}{c}\text { Used mineral } \\
\text { salts }\end{array}$ & \multicolumn{4}{c}{$\begin{array}{c}\text { The content of microelements } \\
\text { additives in water, }\left(\mathbf{m g ~ L}^{-1}\right)\end{array}$} \\
\hline $\mathrm{Se}\left(\mathrm{Na}_{2} \mathrm{SeO}_{4}\right)$ & 0 & 5.0 & 8.5 & 17.0 \\
$\mathrm{Cu}\left(\mathrm{CuSO}_{4} 5 \mathrm{H}_{2} \mathrm{O}\right)$ & 0 & 10.0 & 20.0 & 50.0 \\
$\mathrm{Zn}\left(\mathrm{ZnSO}_{4} 7 \mathrm{H}_{2} \mathrm{O}\right)$ & 0 & 10.0 & 50.0 & 100.0 \\
\hline
\end{tabular}

Determination of total phenolic content (TPC)

Total phenol determination started with preparation of extracts from rye malt. Rye malt was finely ground in the laboratory mill CIATRONIC KSW 2669. Four grams from each sample were extracted for $10 \mathrm{~min}$ in the ultrasound bath (ULTRASONS, SELECTA P) with $40 \mathrm{~mL}$ of solvents ethanol / acetone / water mixture. After centrifugation at $3000 \mathrm{~min}^{-1}$ for $10 \mathrm{~min}$ using the centrifuge MEDITRONIC BL-C, the supernatant was removed and the extraction was repeated once more. The supernatant was collected in a $50 \mathrm{~mL}$ volumetric flask and refilled by solvent till mark. The TPC of the malt extract was determined according to the Folin-Ciocalteu spectrophotometric method with some modifications. First, $0.25 \mathrm{~mL}$ of sample was transferred to a $25.0 \mathrm{~mL}$ volumetric flask containing $6 \mathrm{~mL}$ of $\mathrm{H}_{2} \mathrm{O}$, to which $1.25 \mathrm{~mL}$ of undiluted Folin-Ciocalteu reagent was subsequently added. After $1 \mathrm{~min}, 3.75 \mathrm{~mL}$ of $20 \%$ aqueous $\mathrm{Na}_{2} \mathrm{CO}_{3}$ was added, and the volume was made up to $25.0 \mathrm{~mL}$ with $\mathrm{H}_{2} \mathrm{O}$. The control sample contained all the reaction reagents except the extract. After $2 \mathrm{~h}$ of incubation at $25{ }^{\circ} \mathrm{C}$, the absorbance was measured at $760 \mathrm{~nm}$ wavelength using the spectrophotometer JENWAY 6300 (Singleton et al., 1999). Results were expressed as milligram gallic acid equivalent per 100 gram dry weight (mg GAE $100 \mathrm{~g}^{-1} \mathrm{DW}$ ).

Determination of individual phenolic compounds (HPLC)

Content of phenolic compounds was determined with High Performance Liquid Chromatography (HPLC) Schimadzu LC-20 Prominence (Shimadzu USA Manufacturing Inc, USA), detector DAD SPD-M20A, Solvent Delivery Unit LC-20AD, Column Oven CTO20A, Autosampler SIL-20A, System Controller CBM20A and data system LC solution software.

Preparation of calibration solution: weight in $100 \mathrm{~mL}$ volumetric flask with narrow neck $6.8 \pm 0.1 \mathrm{mg}$ gallic acid, $\quad 7.4 \pm 0.1 \mathrm{mg}$ 3.5-dihydroxybenzoic acid, $\quad 11.4 \pm 0.1 \mathrm{mg}$ 3.4-dihydroxybenzoic acid, $12.0 \pm 0.1 \mathrm{mg}$ catechin, $12.8 \pm 0.1 \mathrm{mg}$ 4-hydroxybenzoic acid, $13.1 \pm 0.1 \mathrm{mg}$ chlorogenic acid, $12.1 \pm 0.1 \mathrm{mg}$ homovanillic acid, $14.5 \pm 0.1 \mathrm{mg}$ vanillic acid, $13.8 \pm 0.1 \mathrm{mg}$ caffeic acid, $16.0 \pm 0.1 \mathrm{mg}$ epicatechin, $18.8 \pm 0.1 \mathrm{mg}$ syringic acid, $9.8 \pm 0.1 \mathrm{mg}$ vanillin, $12.1 \pm 0.1 \mathrm{mg} \quad p$-coumaric acid, $\quad 88.1 \pm 0.1 \mathrm{mg}$ sinapinic acid, $9.2 \pm 0.1 \mathrm{mg}$ ferulic acid, $11.2 \pm 0.1 \mathrm{mg}$ 2-hydroxycinnamic acid, $6.1 \pm 0.1 \mathrm{mg}$ rutin, $10.3 \pm 0.1 \mathrm{mg}$ trans-4-hydroxycinnamic acid, $4.3 \pm 0.1 \mathrm{mg}$ quercetin, $9.1 \pm 0.1 \mathrm{mg}$ luteolin and 9.6 $\pm 0.1 \mathrm{mg}$ kaempherol and fill with HPLC grade CHROMASOLV ${ }^{\circledR}$ methanol till mark and mix.

Parameters of chromatography: the analytical column Perkin Elmer C18, $4.6 \times 250 \mathrm{~mm}, 5 \mu \mathrm{m}$ and temperature of column $+30{ }^{\circ} \mathrm{C}$ were used for separation of polyphenols in wavelength at $278 \mathrm{~nm}$. Injection volume of sample $100 \mu \mathrm{L}$. Mobile phase: A (deionized water), $B$ (HPLC grade CHROMASOLV ${ }^{\circledR}$ methanol) and C (Acetic acid solution for HPLC) in the gradient conditions was used. Start flow rate is $1.0 \mathrm{~mL} \mathrm{~min}{ }^{-1}$.

The obtained calibration chromatogram is given in Figure 1.

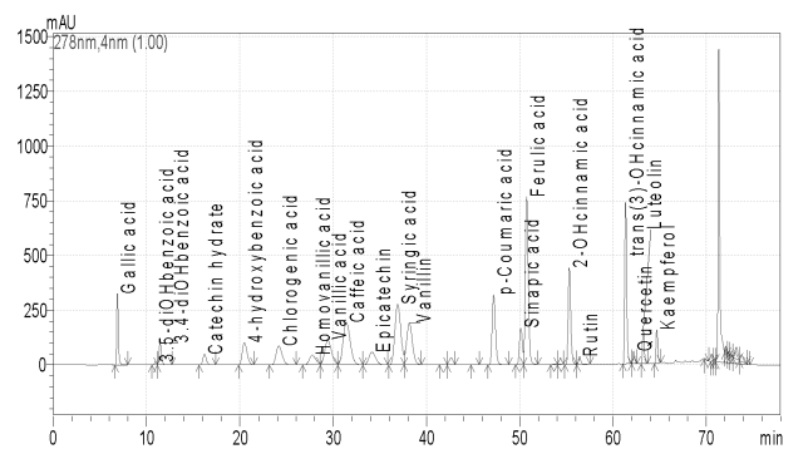

Figure 1. Calibration chromatogram of phenols

Statistical analysis

The statistical analyses of data were carried out using Microsoft Excel for Windows 7.0 (Microsoft Corporation, Redmond, WA). Mean value, standard deviations and significant value were calculated for total phenols and individual phenolic compounds. p-values $<0.05$ were regarded as significant.

\section{Results and Discussion}

To determine content of phenolic compounds in rye malt, rye grain was soaked in varying concentrations of selenium, copper and zinc salt solutions (Table 1).

The content of the total phenolic was higher almost 30 times compared with amount of individual phenolic compounds. It could be explained with spectrophotometric method disadvantages, because using this method we determined not only phenolic compounds but also others compounds containing phenolic groups. The purpose of this article is to give an overview about the influence of different microelements on the tendency of phenolic compounds change in rye malt.

The influence of selenium additives on total and individual phenolic content is presented in Table 2 .

The obtained results (Table 2) show that all analysed selenium additives have positive influence on the content of phenolic compounds in rye malt. The highest content of total phenolic was determined at $17.0 \mathrm{mg} \mathrm{L}^{-1}$ of selenium and this was $37 \%$ more than in the control sample.

The content of individual phenolic compounds was increased about two times. Similar results were found by other authors, suggesting that selenium increased the polyphenol content in plants (Motomura et al., 2008). 
The influence of selenium on total and individual phenolic content in rye malt

\begin{tabular}{lcccc}
\hline \multirow{2}{*}{ Compounds } & \multicolumn{4}{c}{ The content of selenium additive in water, $\mathbf{~ m g ~ L}^{-\mathbf{1}}$} \\
\cline { 2 - 5 } & $\mathbf{0}$ & $\mathbf{5 . 0}$ & $\mathbf{8 . 5}$ & $\mathbf{1 7 . 0}$ \\
\hline Total phenolic compounds, $\mathrm{mg} 100 \mathrm{~g}^{-1}$ & $313.00 \pm 12.00$ & $332.00 \pm 17.00$ & $357.00 \pm 14.00$ & $363.00 \pm 11.00$ \\
Individual phenolic compounds, ${\mathrm{mg} 100 \mathrm{~g}^{-1}}$ & $6.21 \pm 0.54$ & $9.52 \pm 0.72$ & $10.82 \pm 0.42$ & $11.3 \pm 0.68$ \\
\hline
\end{tabular}

The influence of copper on total and individual phenolic content in rye malt

Table 3

\begin{tabular}{lcccc}
\hline \multicolumn{1}{c}{ Compounds } & \multicolumn{4}{c}{ The content of copper additive in water, $\mathbf{~ m g ~}^{-\mathbf{1}}$} \\
\cline { 2 - 5 } & $\mathbf{0}$ & $\mathbf{1 0}$ & $\mathbf{2 0}$ & $\mathbf{5 0}$ \\
\hline Total phenolic compounds, $\mathrm{mg} 100 \mathrm{~g}^{-1}$ & $231.00 \pm 13.00$ & $221.00 \pm 15.00$ & $288.00 \pm 18.00$ & $311.00 \pm 11.00$ \\
Individual phenolic compounds, ${\mathrm{mg} 100 \mathrm{~g}^{-1}}$ & $5.48 \pm 0.23$ & $7.18 \pm 0.42$ & $8.18 \pm 0.48$ & $9.99 \pm 0.61$ \\
\hline
\end{tabular}

Table 4

The influence of zinc on total and individual phenolic content in rye malt

\begin{tabular}{|c|c|c|c|c|}
\hline \multirow{2}{*}{ Compounds } & \multicolumn{4}{|c|}{ The content of zinc additive in water, $\mathrm{mg} \mathrm{L}^{-1}$} \\
\hline & $\mathbf{0}$ & 10 & 50 & 100 \\
\hline Total phenolic compounds, mg $100 \mathrm{~g}^{-1}$ & $297.00 \pm 18.00$ & $288.00 \pm 14.00$ & $233.00 \pm 17.00$ & $275.00 \pm 16.00$ \\
\hline Individual phenolic compounds, mg $100 \mathrm{~g}^{-1}$ & $8.33 \pm 0.38$ & $6.98 \pm 0.56$ & $7.74 \pm 0.49$ & $9.09 \pm 0.41$ \\
\hline
\end{tabular}

The use of copper additives had also positive influence on the content of phenolic compounds in rye malt (Table 3). Obtained results showed that at copper concentration in solution $50 \mathrm{mg} \mathrm{L}^{-1}$ an increase in total phenolic content was $26 \%$ comparing with the control sample. The increase of individual phenolic content was significant $(\mathrm{p}<0.05)$ at all analysed copper concentrations comparing to the control, and the highest phenolic content was observed when the copper concentration in the solution was $50 \mathrm{mg} \mathrm{L}^{-1}$.

Analysing obtained results regarding the zinc additives it is not possible to make common conclusion about its influence on forming of phenols. Experimental results showed (Table 4) that all analysed zinc additives decreased total phenol content in rye malt compared with control sample. On the other hand the highest amount of individual phenolic compounds was observed when the zinc concentration in the solution was $100 \mathrm{mg} \mathrm{L}^{-1}$. At lower concentrations, amount of individual phenolic compounds decreased, compared with control sample. Our results are similar with the results of other studies who found that phenolic content of plants were increasing with increasing levels of microelements $(\mathrm{Cu}$ and $\mathrm{Zn})$ (Hamid et al., 2010; Ganeva, Zozikova 2007; Vinod et al., 2012).

It was identified 19 of phenol-type compounds, of which 14 were phenolic acids: 7 benzoic acid derivatives (gallic acid, $\alpha$-resorcylic acid, protocatechuic acid, $p$-hydroxybenzoic acid, vanillic acid, syringic acid, p-coumaric acid), 6 cinnamic acid derivatives (chlorogenic acid, caffeic acid, sinapic acid, ferulic acid, o-hydroxycinnamic acid, m-hydroxycinnamic acid) and one phenylacetic acid derivative (homovanillic acid). There was also identified four flavonoids (rutin, quercetin, luteolin, kaemferol) and one flavonoid (catechin).

The majority of determined phenolic compounds were less than $0.1 \mathrm{mg} 100 \mathrm{~g}^{-1}$, moreover, in some samples it was not possible to determine all individual phenols, because their content was under the detection limit. The content of only four of phenolic compounds $(\alpha$-resorcylic acid, protocatechuic acid, catechin and kaempferol) were higher than $1 \mathrm{mg} 100 \mathrm{~g}^{-1}$.

The influence of selenium, copper and zinc additives on $\alpha$-resorcylic acid, protocatechuic acid, catechin and kaempferol content in rye malt are shown in Figures 2, 3 and 4.

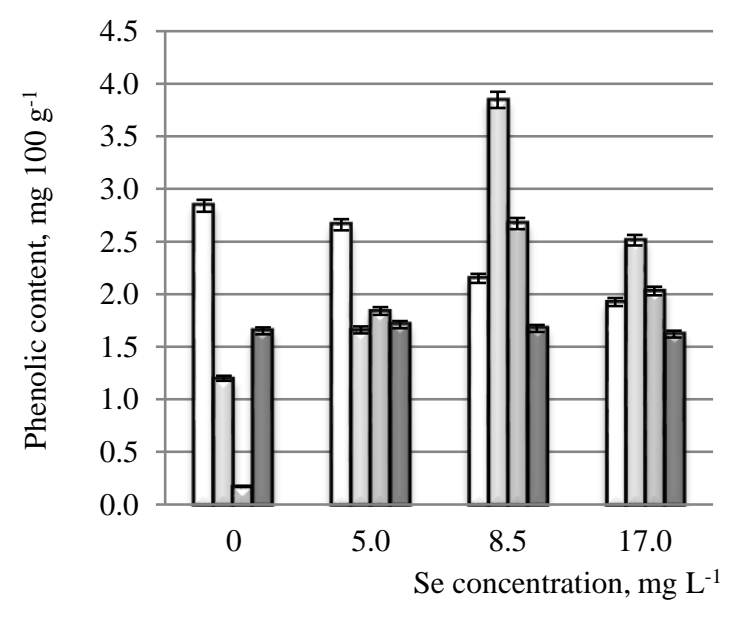

$$
\begin{array}{ll}
\square \alpha \text {-resorcylic acid } & \text { 口Protocatechu } \\
\mathbf{\square C a t e c h i n} & \mathbf{Q K a e m p f e r o l}
\end{array}
$$

Figure 2. The influence of different Se concentration on $\alpha$-resorcylic acid, protocatechuic acid, catechin, and kaempferol content in rye malt

The obtained results (Figure 2) showed that content of $\alpha$-resorcylic acid, protocatechuic acid, catechin and kaemferol in rye malt depends on the Se concentration in solution. Content of protocatechuic acid and catechin increases with increasing Se concentration in solution. At the Se concentration $8.5 \mathrm{mg} \mathrm{L}^{-1}$ the content of protocatechuic acid and catechin acids were the highest

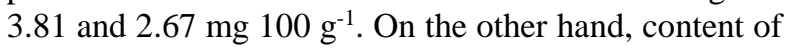


$\alpha$-resorcylic acid decreased with increasing of Se concentration in solution.

The content of $\alpha$-resorcylic acid, protocatechuic acid, catechin and kaemferol in rye malt depended on the $\mathrm{Cu}$ concentration in solution (Figure 3). Content of $\alpha$-resorcylic acid and protocatechuic acids increased with increasing of $\mathrm{Cu}$ concentration in solution. The highest catechin content $\left(2.79 \mathrm{mg} 100 \mathrm{~g}^{-1}\right)$ in rye malt was determined at copper concentration $20 \mathrm{mg} \mathrm{L}^{-1}$.

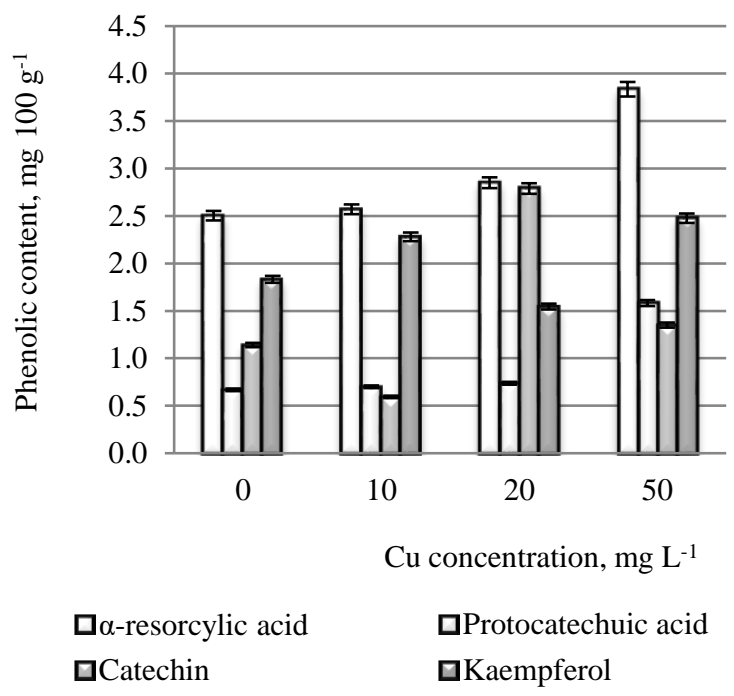

Figure 3. The influence of different $\mathrm{Cu}$ concentration on $\alpha$-resorcylic acid, protocatechuic acid, catechin and kaempferol content in rye malt

The obtained results (Figure 4) showed that $\mathrm{Zn}$ affected the content of $\alpha$-resorcylic acid, protocatechuic acid, catechin and kaemferolin rye malt like other two microelements $(\mathrm{Se}$ and $\mathrm{Cu}$ ) and that degree of influence depended on the $\mathrm{Zn}$ concentration in solution. Content of $\alpha$-resorcylic acid, catechin and kaempherol increased with the increase of $\mathrm{Zn}$ concentration in solution. At the highest $\mathrm{Zn}$ concentration $\left(50 \mathrm{mg} \mathrm{L}^{-1}\right)$ the content of $\alpha$-resorcylic acid, catechin and kaempherol was 3.99,

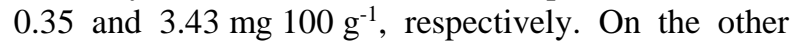
hand, content of protocatechuic acid decreased with the increase of $\mathrm{Zn}$ concentration in solution.

The amount of individual phenolic in rye grain was $2.92 \mathrm{mg} 100 \mathrm{~g}^{-1}$ on average. The amount of identified phenolic compounds in malt control samples ranged from $5.48 \mathrm{mg} 100 \mathrm{~g}^{-1}$ to $8.33 \mathrm{mg} 100 \mathrm{~g}^{-1}$ wich was almost two or three times higher, compared with ungerminated rye grain. Two phenolic compounds (protocatechuic acid and catechin) were not identified in rye grain. The content of kaemferol in rye grain $\left(1.73 \mathrm{mg} 100 \mathrm{~g}^{-1}\right)$ was similar with rye malt control samples (1.65-1.83 mg $100 \mathrm{~g}^{-1}$ ), but content of $\alpha$-resorcylic acid

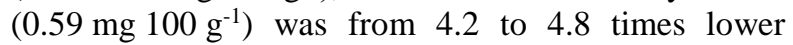
compared with rye malt control samples.

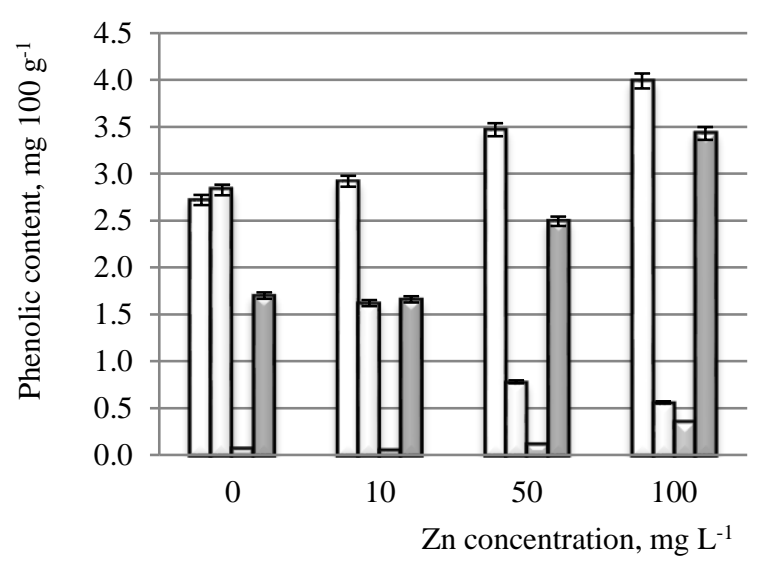

$$
\begin{array}{ll}
\square \alpha \text {-resorcylic acid } & \square \text { Protocatechuic acid } \\
\square \text { Catechin } & \square \text { Kaempferol }
\end{array}
$$

Figure 4. The influence of different $\mathrm{Zn}$ concentration on $\alpha$-resorcylic acid, protocatechuic acid, catechin and kaempferol content in rye malt

This can be explained by the enzymatic release of the bound antioxidants of grain as well as glycosylation reactions during malting and non-enzymatic changes during kilning. Therefore, the levels of extractable phenolic compounds are usually reported to be higher| in malt than in grain. During kilning, the level of flavan-3-ols (catechins) is decreasing, whereas the content of extractable phenolic acids increases (Čechovská et al, 2012).

\section{Conclusions}

Selenium and copper additives had positive influence on the increase of phenolic content in malt. Regarding zinc salt additives we could not make such conclusion. It was identified 19 of phenol-type compounds, of which 14 were phenolic acids, four flavonoids and one flavanoid (catechin). The majority of determined phenolic compounds were in amount less than $0.1 \mathrm{mg} 100 \mathrm{~g}^{-1}$. Only four of phenolic compounds $(\alpha$-resorcylic acid, protocatechuic acid, catechin, and kaempferol) were higher than $1 \mathrm{mg} 100 \mathrm{~g}^{-1}$. The content of $\alpha$-resorcylic acid was higher comparing with other determined phenolic compounds both in control samples and samples with $\mathrm{Se}, \mathrm{Cu}$ and $\mathrm{Zn}$ additives (1.95-2.92 mg $\left.100 \mathrm{~g}^{-1}\right)$. In control samples and samples with $\mathrm{Zn}$ additives catehin content was the lowest $\left(0.06-0.17 \mathrm{mg} 100 \mathrm{~g}^{-1}\right)$. Selenium and copper additives promoted formation of catehin. The amount of individual phenolic compounds in rye grain was almost two or three times lower, compared with control samples of rye malt. Protocatechuic acid and catechin were not detected in rye grain samples. The content of kaemferol in rye grain was similar with rye malt control samples, but content of $\alpha$-resorcylic acid was more than 4 times lower comparing to rye malt control samples.

\section{References}

1. Amarowicz R., Weidner S. (2012) Content of phenolic acid in rye caryopses determined using DAP-HPLC 
method, Czech Journal of Food Science, Vol. 19, p. 201-205.

2. Antonenko K., Kreicbergs V., Duma M., Dimins F., Ozola S., Rudovica V. (2013) The influence of copper on the rye malt quality. Preliminary Proceedings of FaBE 2013: Food and Biosystems Engineering Laboratory. - Larissa, Vol. 2, p. 349-358.

3. Čechovská L., Konečný M., Velíšek J., Cejpek K. (2012) Effect of Maillard reaction on reducing power of malts and beers. Czech Journal of Food Science, Vol. 30, p. 548556.

4. Edney M.J., Izydorczyk M.S. (2003) Malt Types and Products. Encyclopedia of Food Sciences and Nutrition, Vol. 2, p. 3671-3677.

5. Ganeva G., Zozikova E. (2007) Effect of increasing Cu2+ concentrations ong and content of free phenols in two lines of wheat (Triticum Aestivum) with different tolerance. General and Applied Plant Physiology, Vol. 33, p. 75-82.

6. Gani A., Wani S.M., Masoodi F.A., Hameed G. (2012) Whole-grain cereal bioactive compounds and their health benefits: A Review. Journal Food Process Technology, Vol. 3 (3), p. 2-10.

7. Hamid N., Bukhari N., Jawaid F. (2010) Physiological responses of Phaseolus vulgaris to different lead concentrations. Pakistan Journal of Botany, Vol. 42, p. 239-246.

8. Mehrizi M.H., Shariatmadari H., Khoshgoftarmanesh A.H., Dehghani F. (2012) Copper effects on growth, lipid peroxidation, and total phenolic content of Rosemary leaves under salinity stress. Journal of Agricultural Science and Technology, Vol. 14, p. 200-212.

9. Messias R.S., Galli V., Silva S.D., Schirmer M.A., Rombaldi C.V. (2013) Micronutrient and functional compounds biofortification of maize grains. Critical Reviews in Food Science and Nutrition, p. 37-41.

10. Motomura Y., Reyes-Díaz M., Mora M. (2008) Effect of selenite on the total polyphenol content and antioxidative activity of aqueous and ethanolic extracts in sprouts of four agronomic species. Journal of Soil Science and Plant Nutrition, Vol. 8 (1), p. 55-67.

11. Naczk M., Shahidi F. (2014) Extraction and analysis of phenolics in food. Journal of Chromatography A, Vol. 1054, p. 95-111.

12. Ondrejovič M., Chmelova D., Ivanišova D., Drab Š., Psota V. (2014) Evaluation of antioxidant activities of cereals and their malts. Nova Biotechnologicaet Chimica, Vol. 13 (2), p. 172-179.

13. Ozcan T., Akpinar-Bayizit A., Yilmaz-Ersan L., Delikanli B. (2014) Phenolics in human health. International Journal of Chemical Engineering and Applications, Vol. 5 (5), p. 392-396.

14. Reis Giada M.L. (2013) Food phenolic compounds: main classes, sources and their antioxidant power. oxidative stress and chronic degenerative diseases - A role for antioxidants, Chapter 4, Publisher: Intech Publisher, Editor:Josē A. Moralez-Gonzalez, p. 87-112.

15. Singleton V.L., Orthofer R., Lamuela-Raventos R.M. (1999) Analysis of total phenols and other oxidation substrates and antioxidants by means of Folin-Ciocalteu reagent. Methods in Enzymology, Vol. 29 (3), p. 152-178.

16. Vinod K., Awasthi G., Chauhan P.K. (2012) Cu and Zn tolerance and responses of the Biochemical and Physiochemical system of Wheat. Journal of Stress Physiology \& Biochemistry, Vol. 8 (3), p. 203-213. 